\title{
Analysis of Dynamic and Thermodynamic Adsorption of Nanoparticles on Solid Surfaces by Dark-field Light Scattering Measurements
}

\author{
Cho-Chun $\mathrm{Hu}^{\mathrm{a}}$ (胡焯淳), Jia-Ching $\operatorname{Lin}^{\mathrm{a}}$ ( 林家慶), Wei-Lung Tseng ${ }^{\mathrm{b}}$ * (曾韋龍), \\ Ming-Feng Huang ${ }^{\mathrm{c}}$ ( 黃銘峯), Tai-Chia Chiu ${ }^{\mathrm{c}}$ (邱泰嘉) and Huan-Tsung Chang ${ }^{\mathrm{a}, \mathrm{c} *}$ ( 張煥宗) \\ ${ }^{a}$ Department of Natural Science Education, National Taitung University, Taitung 950, Taiwan, R.O.C. \\ ${ }^{\mathrm{b}}$ Department of Chemistry, National Sun Yat-sen University, Kaohsiung 804, Taiwan, R.O.C. \\ ${ }^{\mathrm{c}}$ Department of Chemistry, National Taiwan University, Taipei 106, Taiwan, R.O.C.
}

\begin{abstract}
We have constructed a dark-field light scattering microscope using a very low-cost digital camera to investigate the adsorption of gold nanoparticles (AuNPs) on four different substrates at various $\mathrm{pH}$ values. The substrates used are glass, polycarbonate (PC), poly(dimethylsiloxane) (PDMS), and poly(methyl methacrylate) (PMMA). The coverage of AuNPs on hydrophobic substrates such as PDMS is greater than that on hydrophilic substrates like glass. The adsorption and aggregation of AuNPs on a particular substrate increased upon decreasing the $\mathrm{pH}$ (from 9.0 to 4.0). A greater coverage percentage of AuNPs, but less aggregation, occurs on glass treated with poly(diallyldimethylammonium) (PDDA) than on bare glass. The scattering intensity increases upon increasing the number of layers of adsorbed AuNPs on glass that was treated sequentially with AuNPs and PDDA. When compared to UV-Vis absorption, dark-field microscope provides greater sensitivity and qualitative surface information.
\end{abstract}

Keywords: Dark-field microscope; Nanoparticles; Monolayer; Multilayer; Poly(diallyldimethylammonium).

\section{INTRODUCTION}

Nanostructured materials, such as gold nanospheres, gold/silver nanorods, and gold nanowires, have gained a great deal of attention because of their unique chemical and physical properties. ${ }^{1-3}$ Differently sized and shaped gold nanoparticles (AuNPs) may be functionalized readily with a variety of molecules, including polymers, proteins, and DNA. Indeed, biofunctionalized AuNPs are useful for sensing DNA and proteins based on absorption, fluorescence, and Raman scattering, as well as for the separation of biomolecules. ${ }^{4-9}$ The assays can be conducted in either homogeneous or heterogeneous formats; when they are conducted in heterogeneous formats, such as surface plasmon absorption, total internal fluorescence, and surfaceenhanced Raman scattering, the (functionalized) AuNPs are usually immobilized on solid surfaces. ${ }^{7-9}$ The quality of adsorption plays an important role in determining the sensitivity and reproducibility of the assays. To achieve uniform and complete surface coverage of AuNPs, prior to immobilization the solid surfaces are treated with molecules that possess pendant functional groups, such as $\mathrm{SH}$ and $\mathrm{NH}_{2}$ units, that can form strong bonds with AuNPs. For glass surfaces, organosilanes are commonly used because they form a stable monolayer on the surface through strong Si-O-Si covalent bonds. ${ }^{10}$ Alternatively, dynamic adsorption of oppositely charged polymers, such as poly(diallyldimethylammonium) (PDDA), polyethylenimine, and poly(sodium 4-styrenesulfonate), is employed to treat the surfaces of glass and polymeric substrates such as polycarbonate (PC), poly(dimethylsiloxane) (PDMS), and poly(methyl methacrylate) (PMMA). ${ }^{11-14}$ Recently, we demonstrated the importance of treating the surface of PMMA chips with AuNPs in the separation of DNA through microchip capillary electrophoresis. ${ }^{15}$ In that study, we obtained improved reproducibility and resolution for DNA separation using a microchannel that had been coated with multilayers of polymers and AuNPs.

Dynamic coating of polymers and AuNPs on substrates is governed by various parameters, including the concentration and $\mathrm{pH}$ of the polymer (or organosilane) solution, the concentration, size, and nature of the AuNPs, the

\footnotetext{
* Corresponding author. Tel and Fax: 011-886-2-3366-1171; E-mail: changht@ntu.edu.tw
} 
nature and concentration of the salt, and the adsorption time and temperature. For the adsorption of AuNPs, these parameters play an important role in determining the surface coverage, interparticle distance, and surface morphology. ${ }^{16,17}$ A variety of techniques are commonly used to characterize the adsorption of AuNPs on solid surfaces, such as UV-Vis absorption spectroscopy, ${ }^{18} \mathrm{X}$-ray photoelectron spectroscopy, ${ }^{19}$ ellipsometry, ${ }^{20}$ transmission electron microscopy (TEM), ${ }^{21}$ scanning electron microscopy (SEM), ${ }^{18,22}$ and atomic force microscopy (AFM). ${ }^{23}$ Although UV-Vis absorption spectroscopy is the simplest and cheapest approach for observing increases in absorbance as a function of immersion time and the growth of multilayer films, it cannot provide detailed information on such features as the degree of aggregation of AuNPs or the roughness and uniformity of the surface. TEM and SEM are powerful techniques for characterizing nanostructured materials, but they both suffer from an inability to provide topographic information concerning the AuNP films. In contrast, AFM has proven to be a powerful tool for measuring surface coverage and height differences in nanoparticle films. ${ }^{24}$ Although TEM, SEM, and AFM all provide excellent resolution, they are expensive, not readily accessible, and generally work better for dry surfaces. In addition, it is sometimes necessary to use tedious sample preparation techniques and to consider special demands brought about by the nature of the solid substrates. Thus, there is a high demand for techniques that are simple, sensitive, and rapid, that have low cost, and provide a high resolution when investigating the adsorption of nanostructured materials under various environmental conditions (dry or wet, electrically conductive or nonconductive, and soft or hard).

In this paper, we demonstrated the measurements of the surface coverage of AuNPs on PC, PDMS, and PMMA and detected their morphologies by using a dark-field microscope (DFM) that was built in this lab. By using the DFM system, several advantages have been achieved, including ease of sample preparation, low cost, rapidity, and the capability of detecting low concentrations of large biomolecules. $^{25}$

\section{RESULTS AND DISCUSSIONS}

\section{Characterization of AuNPs adsorbed on different substrates}

To test the features of the DFM system, we investigated the dynamic adsorption of these AuNPs onto the surfaces of four different substrates: glass, PC, PDMS, and PMMA. Fig. 2a indicates that the adsorption of AuNPs on

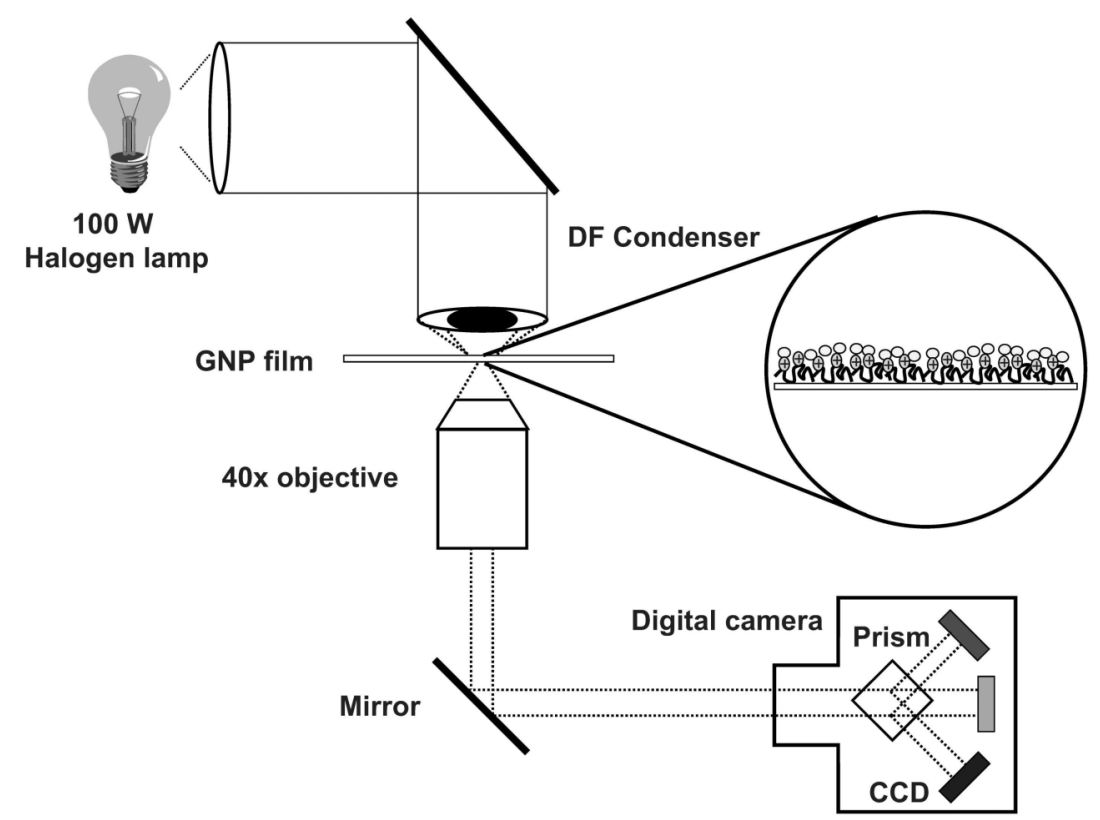

Fig. 1. Schematic diagram of a dark-field microscopy system for use in surface characterization and the monitoring of particle growth rates on surfaces. 
the hydrophobic substrates, such as PDMS [contact angle $(\theta)=$ approx. $\left.110^{\circ}\right]$ and $\mathrm{PC}\left(\theta=\operatorname{approx} .70^{\circ}\right)$, was more effective than that on a relatively hydrophilic surface, such as glass $\left(\theta=\right.$ approx. $\left.19^{\circ}\right)$, at the same value of $\mathrm{pH}^{26,27} \mathrm{We}$ note that a surface having a small contact angle is relatively hydrophilic, while that having a large contact angle is relatively hydrophobic. The AuNPs in the magnified DFM image of the samples adsorbed on the glass at $\mathrm{pH} 9.0$ appear to have greater sizes than do the actual AuNPs. This phenomenon arises because the optically imaged size of the AuNPs is diffraction-limited to approx. $\lambda / 2 \mathrm{NA} .{ }^{28}$ For example, the optically imaged size of the AuNPs is $535 \mathrm{~nm} /(2 \times 0.55)=$ $489 \mathrm{~nm}$ when we used the maximum SPR wavelength for this measurement (i.e., it is about nine times larger than the physical diameter of the AuNPs). The AuNP adsorption on the four substrates increases with decreasing the $\mathrm{pH}$ because the surface charges of the AuNPs, glass, and PC all decrease upon decreasing the $\mathrm{pH}$; i.e., they are more hydrophobic at low values of $\mathrm{pH}$. These results suggest that the AuNPs interact strongly with hydrophobic surfaces. At $\mathrm{pH}$

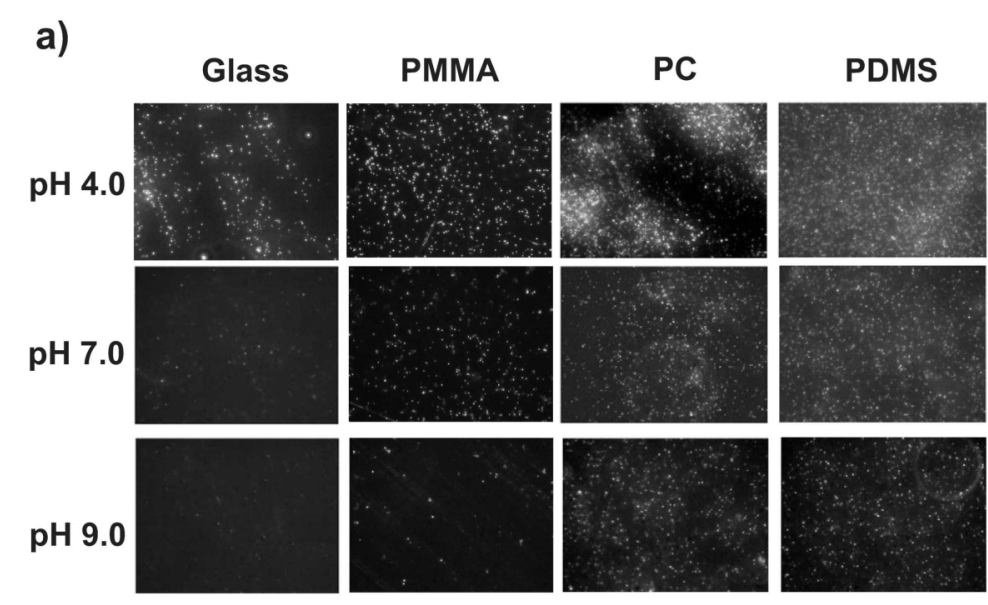

b)

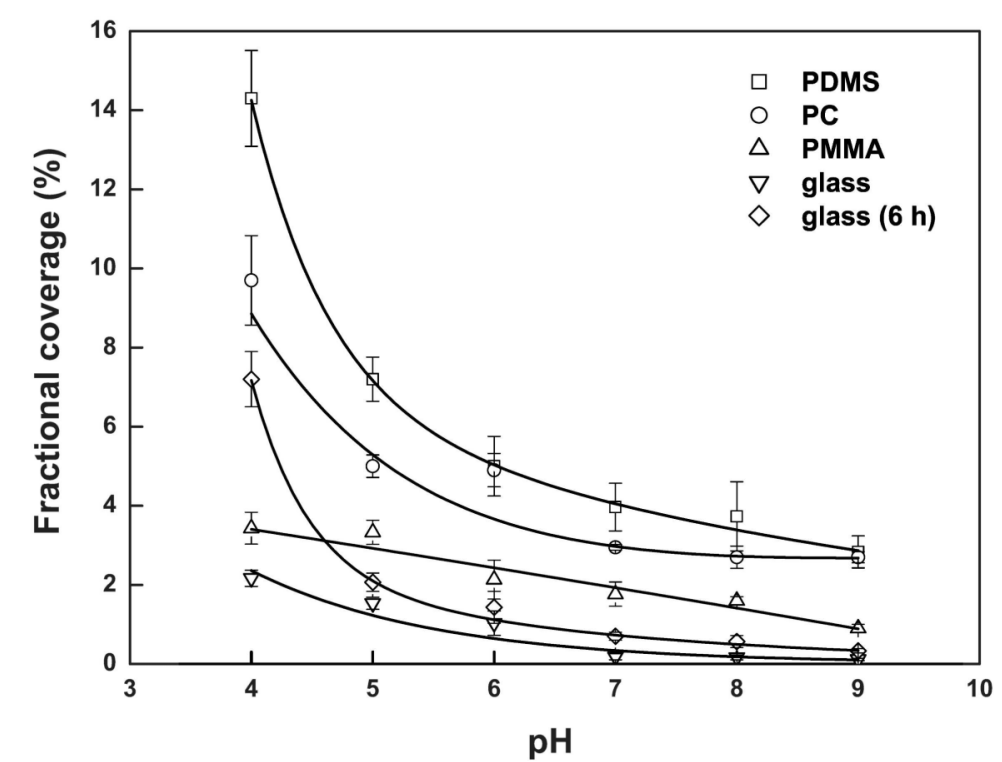

Fig. 2. (a) Scattering images of AuNPs adsorbed on glass, PMMA, PC, and PDMS at different values of pH. (b) Surface coverage of AuNP films on the four different substrates as a function of pH. $4.9 \mathrm{pM}$ AuNPs were prepared in $10 \mathrm{mM}$ glycine solution and were deposited for $60 \mathrm{~min}$. Exposure time: $0.25 \mathrm{~s}$; scattering detection area using a $40 \mathrm{x}$ objective: $140 \times 105 \mu \mathrm{m}$, which corresponds to 2592 (horizontal) $\times 1944$ (vertical) pixels. 
5.0, some spots display a yellow color and a strong scattering intensity, which indicate that a small number of AuNPs have aggregated. Such aggregation of AuNPs is more apparent on the hydrophobic surfaces than on the hydrophilic ones. Fig. $2 b$ indicates that the surface coverage of the AuNPs increases upon decreasing the $\mathrm{pH}$ and increasing the hydrophobicity of the substrates. The coverages for glass and PDMS surfaces are 0.1 and $2.8 \%$ at $\mathrm{pH} 9.0$ and are 2.1 and $14.3 \%$ at $\mathrm{pH} 4.0$, respectively. We note that the surface coverages increased further with increasing the reaction (adsorption) time; they reached equilibrium after approx. $6 \mathrm{~h}$. The maximum surface coverage percentages for glass and PDMS were 7.2 and $25.1 \%$ at $\mathrm{pH} 4.0$, respectively. We found, however, that aggregation of AuNPs (i.e., the formation of multilayers) also increased upon increasing the reaction time.

\section{a) $1 \mathrm{~min}$}

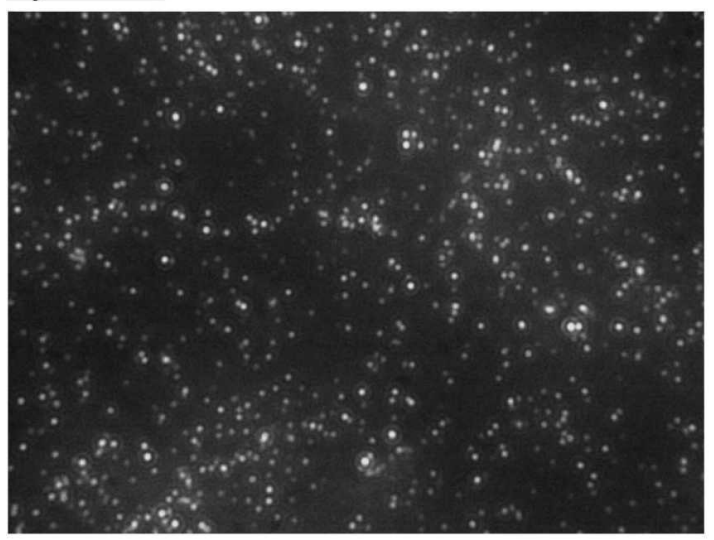

\section{c) $\mathbf{2 4 0} \mathrm{min}$}

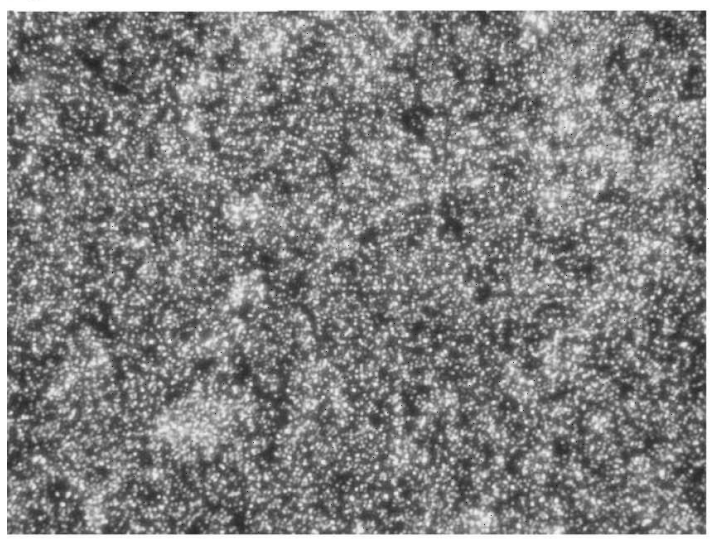

\section{Control of surface coverage and morphology}

To decrease the degree of aggregation of the AuNPs while achieving a greater coverage on the solid surface, we treated the glass surfaces coated with PDDA. PDDA remains a highly charged polyelectrolyte over a wide range of values of $\mathrm{pH}$ and it provides a lower surface roughness than does either polyethylenimine or APTES when it is used to treat glass surfaces. ${ }^{29}$ The surface coverage of AuNPs on PDDA-modified glass is also higher than those on APTES- and dendrimer-treated glass. Figs. 3a-c display the time evolution of the adsorption of AuNPs on a PDDAtreated glass. Fig. 3d indicates that the surface coverage increased upon increasing the reaction time and reached a plateau of $34 \%$ after $4 \mathrm{~h}$. We note that the surface coverage is lower than the reported value of approx. $55 \%$, probably because of the stronger repulsion among the AuNPs. ${ }^{30}$ For

\section{b) $60 \mathrm{~min}$}

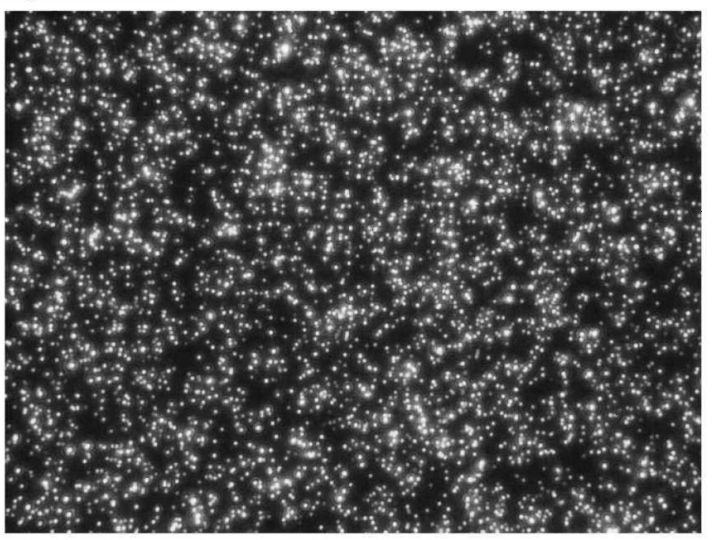

d)

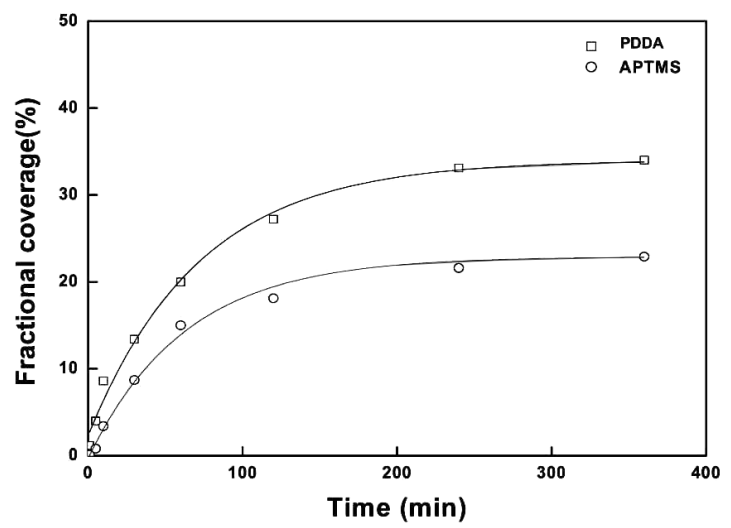

Fig. 3. Scattering images of AuNP films on a PDDA-glass. Deposition times for $4.9 \mathrm{pM}$ AuNPs prepared in $10 \mathrm{mM}$ glycine (pH 9.0): (a) $1 \mathrm{~min}$, (b) $60 \mathrm{~min}$, and (c) $240 \mathrm{~min}$. (d) Surface coverage of AuNP films on APTES-glass (triangles) and PDDA-glass (squares) surfaces as a function of deposition time. The other conditions are the same as those described in Fig. 2. 
comparison, Fig. $3 \mathrm{~d}$ also depicts the time evolution of the surface coverage of AuNPs on an APTES-treated glass. The AuNP adsorption rates on the two different surfaces are both fast during the first two hours of reaction. We note that a greater coverage of AuNPs and a lower degree of AuNP aggregation occurred on the PDDA-treated glass relative to the APTES-treated and bare glass. Although AuNPs tend to adsorb onto surfaces that are occupied by AuNPs, which, thus, induces aggregation of AuNPs, the highly positively charged surface of the PDDA-treated glass minimizes aggregation of AuNP clusters. ${ }^{29}$

Next, we investigated AuNP adsorption on PDDAtreated glass at different values of $\mathrm{pH}$ (4.0-9.0, $10 \mathrm{mM}$ glycine); Fig. 4 depicts the results. The representative DFM images depicted in Figs. 4a-c demonstrate that the coverage percentage of the AuNPs at pH 7.0 is lower than those at $\mathrm{pH} 5.0$ and 9.0. Fig. $4 \mathrm{~d}$ reveals that a greater AuNP surface coverage was obtained at $\mathrm{pH} 9.0$, mainly because of strong electrostatic interactions between the negatively charged AuNPs (they were capped with citrate ions) and the positively charged PDDA molecules. In contrast to the situation in Fig. 2b (bare glass), the AuNP surface coverage was higher at $\mathrm{pH} 5.0$ than it was at values of $\mathrm{pH}$ ranging from 5.0 to 8.0. We note that hydrophobic patches, hydrogen bonding, and Coulombic interactions all play some roles in determining the extent of AuNP adsorption. Upon decreasing the $\mathrm{pH}$, the concentration of surface negative charges of the AuNPs decreases, whereas the positive charges of PDDA remain almost unchanged. ${ }^{29}$ Thus, the first of these two forces become more important at low values of $\mathrm{pH}$. In addition, we must also carefully consider that the interactions that occur between the glass surface and the PDDA molecules and the structure of the PDDA adsorbed on the glass surface (an extended coil and a globular structure of PDDA at low and high $\mathrm{pH}$, respectively) both change at different values of $\mathrm{pH} .{ }^{31} \mathrm{We}$ note that the surface cover-

\section{a) $\mathrm{pH} 5.0$}

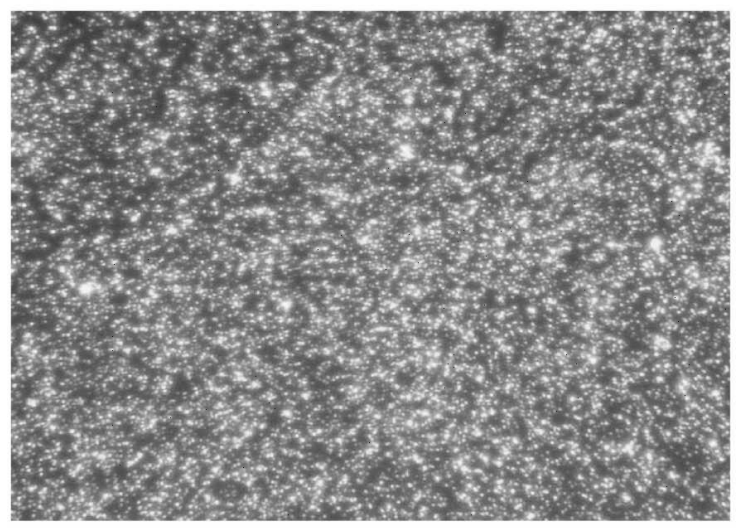

\section{c) $\mathrm{pH} 9.0$}

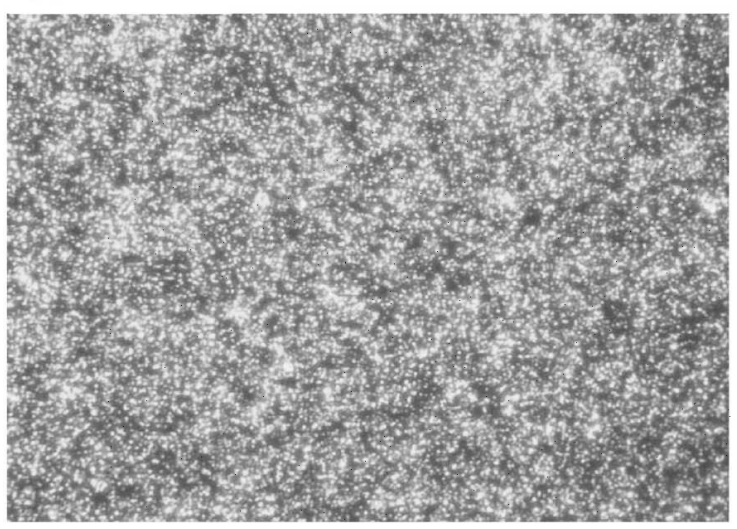

\section{b) $\mathrm{pH} 7.0$}

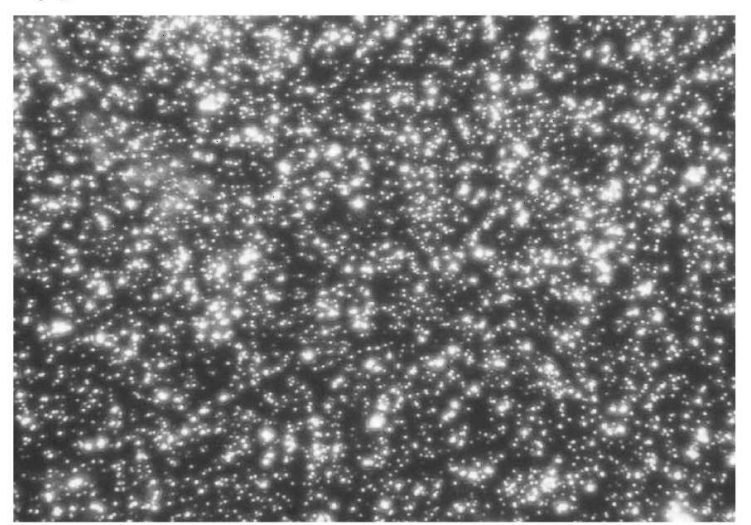

d)

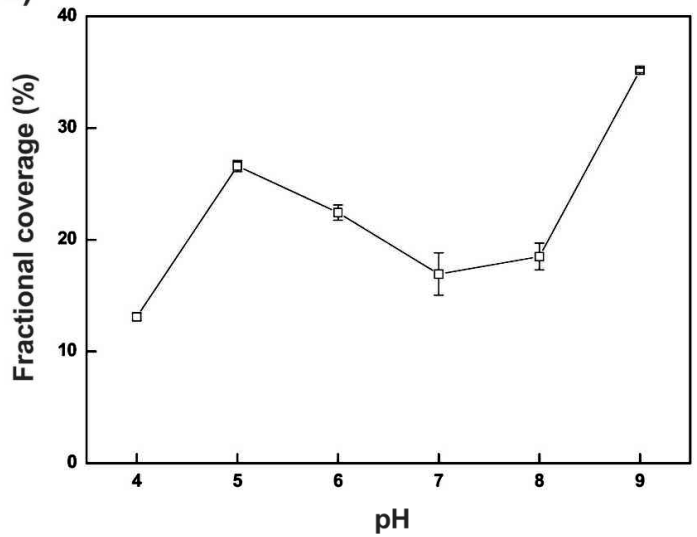

Fig. 4. Scattering images of AuNP films assembled on PDDA-glass at different values of pH: (a) pH 5.0, (b) pH 7.0, and (c) $\mathrm{pH}$ 9.0. (d) Surface coverage of AuNPs on PDDA-glass surfaces as a function of pH. Deposition time: $6 \mathrm{~h}$. The other conditions are the same as those described in Fig. 2. 
age of AuNPs is lower at $\mathrm{pH}$ 4.0. It is also important to highlight the fact that the AuNP film became thicker and less organized, with a greater extent of aggregation distributed all over the surface, at low $\mathrm{pH}$.

We analyzed the data obtained for AuNP aggregation on the PDDA-treated glass at different values of $\mathrm{pH}$ and reaction time according to the following equation: ${ }^{32}$

$$
1 / A=1 / A_{\max }+K_{\mathrm{M}} /\left(A_{\max } \times t\right)
$$

where $A_{\max }$ is the maximum surface coverage, $A$ is the surface coverage at different deposition times $(t)$, and $K_{\mathrm{M}}$ is the rate of the formation of a multiplayer (i.e., AuNP aggregation). Table 1 indicates that the plots of $1 / A$ vs $1 / t$ at different values of $\mathrm{pH}$ are linear $\left(R^{2}>0.968\right)$, other than that obtained at $\mathrm{pH}$ 7.0. The values of $K_{\mathrm{M}}$ increased with decreasing the $\mathrm{pH}$, which indicates either that AuNP aggregation occurs to a greater extent or that formation of the AuNP multilayer occurs at low $\mathrm{pH}$. At $\mathrm{pH} 9.0$, the value of $K_{\mathrm{M}}$ of 0.32 demonstrates that the rate of formation of the first monolayer is three times more facile kinetically than is that of the multilayer. In contrast, the value of $K_{\mathrm{M}}$ of 2.96 at $\mathrm{pH}$ 4.0 suggests that the formation of AuNP aggregates is three times faster than the adsorption of AuNPs on the PDDAtreated glass surface.

We further tested the features of the lab-made DFM system through an investigation of the formation of multiple layers of AuNPs and PDDA on glass surfaces. A molecular layer-by-layer self-assembly technique can not only enhance the stability and penetrability of particulate materials absorbed on the solid surface but also allow fabrication of multi-layers of different nanocomposites in a very controlled way by using templates. ${ }^{33,34}$ Figs. 5a-c exhibit DFM images for the (AuNP/PDDA $)_{n}$ glass, where $\mathrm{n}=1,4$, and 8 , respectively. The scattering intensity increased linearly (Fig. 5d) with increasing the number of deposited AuNP/PDDA bilayers. For comparison, Fig. 5d also depicts the UV-Vis absorbance at $548 \mathrm{~nm}$ plotted against the number of the bilayers of AuNPs/PDDA. These results support our DFM data. Although the aggregated form and the number of AuNPs affect the scattering intensity on the surface, their effect is trivial in this study since the scattering intensity of the detection area about $140 \times 105 \mu \mathrm{m}$ was collected and integrated by ImageJ programs. The linear relationship between the light scattering signal and the multilayer numbers clearly suggests that the DFM system holds
Table 1. Values of $K_{\mathrm{M}}$, linear regression coefficient $\left(R^{2}\right)^{\mathrm{a}}$, and maximum surface coverage $\left(A_{\max }\right)$ on PDDA-glass and APTES-glass at different values of $\mathrm{pH}$

\begin{tabular}{llll}
\hline $\mathrm{pH}$ & $K_{\mathrm{M}}$ & $R^{2}$ & $A_{\max }(\%)$ \\
\hline 4 & 2.96 & 0.9681 & 16.1 \\
5 & 1.24 & 0.9860 & 29.6 \\
6 & 0.51 & 0.9984 & 21.03 \\
7 & 0.78 & 0.8618 & 9.87 \\
8 & 0.71 & 0.9979 & 22.9 \\
9 & 0.32 & 0.9949 & 23.5 \\
$9^{\mathrm{b}}$ & 1.36 & 0.9969 & 31.3 \\
\hline
\end{tabular}

${ }^{\text {a }}$ Linear plots according to Eq. 1.

b $25 \%$ APTES.

great potential for monitoring the assembly performance on the solid substrates when using metal nanoparticles, quantum dots, and silica nanoparticles.

\section{Advantages and Disadvantages of DMF}

We compared our DFM technique to the use of AFM, which is a very versatile imaging technique that has no limitations with respect to the characterization of the composition or size of the sample surface. The image (not shown) taken by AFM indicates that AuNP aggregation leads to the formation of gold clusters on the PDDA-treated glass (at $\mathrm{pH} 9.0$ ) after a deposition time of $6 \mathrm{~h}^{35}$ The DFM, however, provides a poorer resolution than does the AFM. The AFM image clearly displays aggregation of a number of AuNPs in each cluster. The poor resolution of the DFM image is due to the diffraction limit; interactions between the photons scattering from different AuNPs in each cluster cause a loss of resolution. The ability to observe gold clusters over a wider area when using the DFM technique indicates that we might gain more information for surface-enhanced Raman scattering when both techniques are applied. ${ }^{36} \mathrm{Ta}-$ ble 2 provides a comparison of DFM in relation to other common techniques: AFM, SEM, and TEM. Compared with AFM, which usually takes about 8.5 min to scan an area of $1-10 \mu \mathrm{m}^{2}$ at a rate of $1 \mathrm{~Hz}$, DFM takes less than $10 \mathrm{~s}$ to provide an image with the view area of $140 \times 105 \mu \mathrm{m}^{2}$. Although DFM is faster than AFM, it cannot distinguish between particles having sizes smaller than approx. $50 \mathrm{~nm}$ based on the color of the scattering light. The resolution of DFM images can be improved further by using a highresolution digital camera $\left(1.25 \times 10^{7}\right.$ pixels $)$ and a highmagnification objective $(100 x)$. We must emphasize that relative to the other three techniques, DFM provides the ad- 


\section{a) 1 layer}

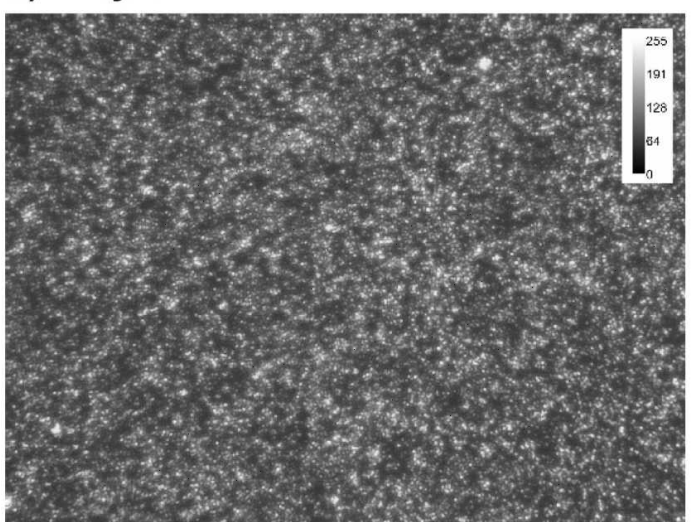

c) 8 layer

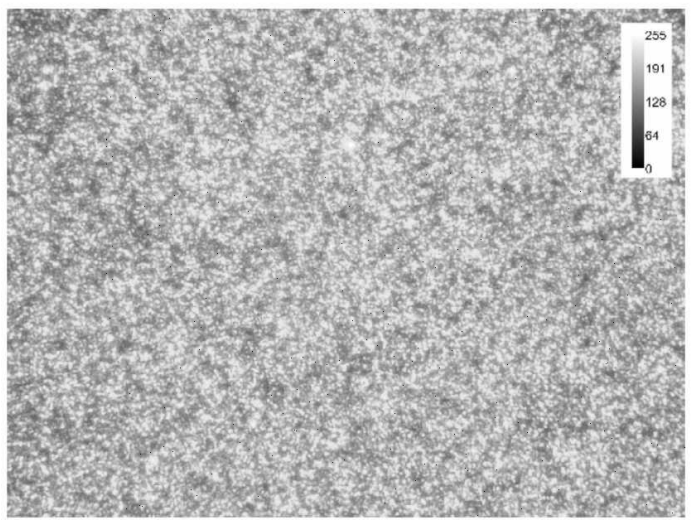

b) 4 layer

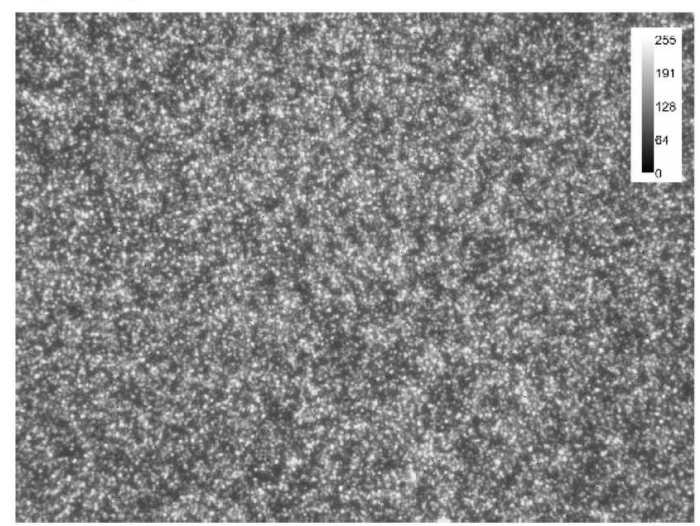

d)

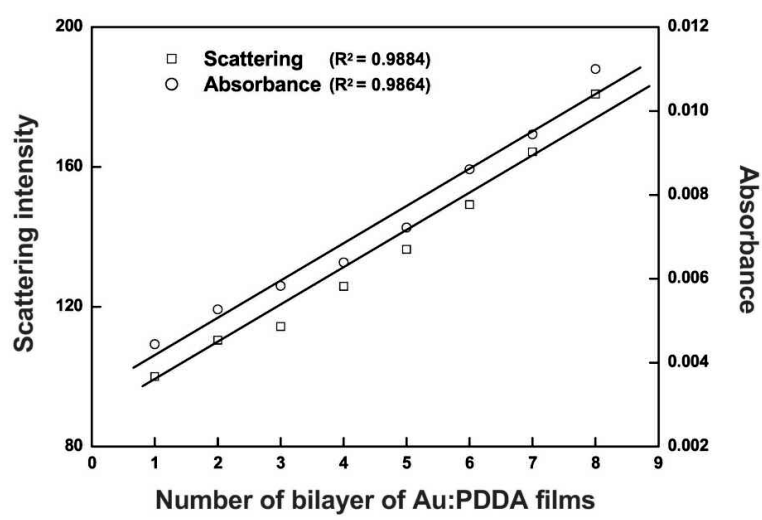

Fig. 5. Scattering images of (AuNP/PDDA $)_{n}$ films on glass: (a) one layer, (b) four layers, and (c) eight layers. (d) Scattering intensity (left) and absorbance (right) as a function of the number of layers. Exposure time: $0.067 \mathrm{~s}$. The other conditions are the same as those described in Fig. 2.

vantages of ease of sample preparation, low cost, fast analyses, and the ability to sense macromolecules in aqueous solution when using biofunctional NPs, such as AuNPs or silica NPs. ${ }^{37}$

\section{EXPERIMENTAL SECTION}

\section{Chemicals}

Sodium tetrachloroaurate(III) dehydrate was obtained from Sigma (St. Louis, MO). Trisodium citrate $\left(\mathrm{p} K_{\mathrm{a} 1}=\right.$ $3.128, \mathrm{p} K_{\mathrm{a} 2}=4.761$, and $\left.\mathrm{p} K_{\mathrm{a} 3}=6.396\right)$ was obtained from Riedel-de Haen (Seelze, Germany). Glycine ( $\mathrm{p} K_{\mathrm{a} 1}=2.35$ and $\left.\mathrm{p} K_{\mathrm{a} 2}=9.778\right)$ was purchased from ICN Biomedicals Inc. (Aurora, OH). PDDA (Mw 100,000-200,000), 3-aminopropyltriethoxysilane (APTES), $\mathrm{NaOH}, \mathrm{HCl}$, and sodium chloride were purchased from Aldrich (Milwaukee,
WI). Glycine buffers were prepared at various $\mathrm{pH}$ values using 1.0 M solution of $\mathrm{HCl}, \mathrm{NaOH}$, and sodium chloride. In each case, the final concentration of glycine was $10 \mathrm{mM}$.

\section{Preparation of AuNPs and PDMS}

The 56-nm AuNPs with the concentration of $\sim 49 \mathrm{pM}$ $\left(2.96 \times 10^{13}\right.$ particles/L) were prepared as described previously. ${ }^{38}$ TEM measurements (not shown) confirmed that the size of the AuNPs was $56( \pm 8 \%) \mathrm{nm}$. The AuNP solution was diluted tenfold in $10 \mathrm{mM}$ glycine solutions $(\mathrm{pH}$ 4.0-9.0). PDMS was prepared according to product information from a Sylgard 184 silicone elastomer kit (Dow Corning, Midland, MI) and cured at $80^{\circ} \mathrm{C}$ for 1 hour.

\section{Deposition of AuNPs on Different Substrates}

PC, PMMA, and PDMS surfaces were cleaned with compressed air and rinsed with water, while the glass sur- 
Table 2. Comparing DFM with other microscopy techniques for the characterization of nanoparticle films

\begin{tabular}{lcccc}
\hline & AFM & DFM & SEM & TEM \\
\hline Detection area $\left(\mu \mathrm{m}^{2}\right)$ & $0.5-100$ & $45-140$ & - & - \\
Resolution $(\mathrm{nm})$ & $1-195$ & $21-54$ & 1 & 0.1 \\
Analysis time (s) & $510^{\mathrm{a}}$ & $<10$ & $<600$ & $<360$ \\
Typical cost (USD) & $1-2 \times 10^{5}$ & $10^{4}$ & $2-4 \times 10^{5}$ & $5 \times 10^{5}$ \\
Sample preparation & Easy & Very easy & Easy & Difficult \\
In fluid & Yes & Yes & No & No \\
Surface morphology & Yes & Yes & No & No \\
Biosensing (applicability) & Good & Excellent & Poor & Poor \\
\hline a At a scan rate of $1 \mathrm{~Hz}$. & & & &
\end{tabular}

faces were cleaned with freshly prepared "piranha" solution [ $98 \% \mathrm{H}_{2} \mathrm{SO}_{4} / 30 \% \mathrm{H}_{2} \mathrm{O}_{2}$ (3:1); DANGEROUS in contact with organic materials] for $30 \mathrm{~min}$, rinsed extensively with water, and then finally dried under a stream of nitrogen. Prior to the immobilization of AuNPs for $1 \mathrm{~h}$, the substrates were equilibrated with glycine solutions ( $\mathrm{pH}$ 4.09.0) at room temperature for $10 \mathrm{~min}$. PC, PMMA, and PDMS plates were then dipped in the AuNP solutions (4.9 $\mathrm{pM}$; $\mathrm{pH}$ 4.0-9.0) for 1-360 min.

\section{Monolayers}

The glass surface was modified using positively charged PDDA $(0.2 \%, 0.5 \mathrm{M} \mathrm{NaCl})$ or APTES $(25 \%$, absolute ethanol), respectively. The glass plates were separately dipped in $0.2 \%$ PDDA or $25 \%$ APTES overnight and then rinsed with water for $1 \mathrm{~min}$. The AuNPs were deposited on the PDDA or APTES glass by dipping in the AuNP solutions (4.9 $\mathrm{pM} ; \mathrm{pH} 9.0$ ) for 1-360 $\mathrm{min}$ and the glass was rinsed with water for $1 \mathrm{~min}$. The adsorption of AuNPs on the glass modified with PDDA was performed at the different values of $\mathrm{pH}$ (4.0-9.0, $10 \mathrm{mM}$ glycine).

\section{Multilayers}

Layer-by-layer assemblies of (AuNP/PDDA) ${ }_{n}$ films were fabricated by dipping a glass alternately into $4.9 \mathrm{pM}$ AuNP (10 mM glycine, $\mathrm{pH} 9.0$ ) and aqueous PDDA solutions $(0.2 \%, 0.5 \mathrm{M} \mathrm{NaCl})$, each for $2 \mathrm{~h}$, with intermediate washing (water) and drying (nitrogen stream). ${ }^{16}$ We repeated this process to obtain the desired number of AuNP/ PDDA bilayers.

\section{Instrumentation}

A Dimension 3100 (Digital Instruments, Inc. Santa Barbara, CA) operating in the tapping mode with a scan rate of $1 \mathrm{~Hz}$ was used to conduct AFM measurements in air. A double-beam UV-visible spectrophotometer (Cintra 10e, GBC Scientific Equipment Pty Ltd., Dandenong, Victoria, Australia) was utilized to measure the absorbance of AuNP solutions and layer-by-layer assemblies of (AuNP/PDDA) films. The TEM images of as-prepared AuNPs were collected using an H7100 TEM (Hitachi High-Technologies Corp., Tokyo, Japan) operating at $75 \mathrm{keV}$.

In our lab-made DFM system (Fig. 1), which contains an Olympus IX70 inverted microscope (Tokyo, Japan) and is equipped with a low-cost digital camera (Coolpix 5400, Nikon, Tokyo, Japan), white light from a 100-W halogen lamp and a focusing lens within a condenser are angled with respect to the objective $(40 \mathrm{x}$; numeric apertures $=$ 0.55 ) so that the illuminating light does not directly enter the objective; this arrangement results in a low background. ${ }^{39}$ We used the ImageJ program (http://rsb.info.nih. gov/ij/) to analyze the images. First, we determined the threshold value of the system based on the difference of the scattering intensity of AuNPs from that of the surface. Then, the surface coverage area of AuNPs on the substrates was calculated by using the Image/Adjust/Threshold function in the ImageJ program. Also, in the case of layer-bylayer self-assembly technique, the area of scattering images about $(140 \times 105 \mu \mathrm{m})$ was converted to a gray level image (255 levels) by a program developed using ImageJ. Then, the scattering intensity of the detection area was integrated with the aid of ImageJ programs.

\section{CONCLUSIONS}

We have applied DFM using a very low-cost digital camera to investigate the formation of AuNP films on dif- 
ferent surfaces. Unlike UV-vis absorption measurements, DFM measurements provide both quantitative and qualitative information of nanomaterials on solid substrates. Although DFM can be used to monitor the real-time growth of nanoparticles on various surfaces (hard or soft, dry or wet, and electrically conductive or nonconductive, its resolution is poor. Our results reveal that the dynamic adsorption of AuNPs on hydrophilic surfaces is more uniform than it is on hydrophobic ones. With decreasing $\mathrm{pH}$ values, AuNP aggregation or formation of AuNP multilayer occurs on solid substrates to a greater extent.

\section{ACKNOWLEDGEMENTS}

This study was supported by the National Science Council of the Republic of China under contracts NSC 952113-M-002-026-MY3 and NSC 95-2113-M-110-020.

Received November 16, 2006.

\section{REFERENCES}

1. Daniel, M.-C.; Astruc, D. Chem. Rev. 2004, 104, 293.

2. Burda, C.; Chen, X.; Narayanan, R.; El-Sayed, M. A. Chem. Rev. 2005, 105, 1025.

3. Murphy, C. J.; Sau, T. K., Gole, A. M.; Orendorff, C. J.; Gao, J.; Gou, L.; Hunyadi, S. E.; Li, T. J. Phys. Chem. 2005, 109, 13857.

4. Li, H.; Rothberg, L. J. Anal. Chem. 2004, 76, 5414.

5. Cao, Y. C.; Jin, R.; Nam, J.-M.; Thaxton, C. S.; Mirkin, C. A. J. Am. Chem. Soc. 2003, 125, 14676.

6. Huang, M.-F.; Kuo, Y.-C.; Huang, C.-C.; Chang, H.-T. Anal. Chem. 2004, 76, 192.

7. Frederix, F.; Friedt, J.-M.; Choi, K.-H.; Laureyn, W.; Campitelli, A.; Mondelaers, D.; Maes, G.; Borghs, G. Anal. Chem. 2003, 75, 6894.

8. Tian, S.; Liu, J.; Zhu, T.; Knoll, W. Chem. Mater. 2004, 16, 4103.

9. Vo-Dinh, T.; Stokes, D. L.; Griffin, G. D.; Volkan, M.; Kim, U. J.; Simon, M. I. J. Raman Spectrosc. 1999, 30, 785.

10. Doron, A.; Katz, E.; Willner, I. Langmuir 1995, 11, 1313.

11. Malikova, N.; Pastoriza-Santos, I.; Schierhorn, M.; Kotov, N. A.; Liz-Marzan, L. M. Langmuir 2002, 18, 3694.

12. Barker, S. L. R.; Tarlov, M. J.; Canavan, H.; Hickman, J. J.;
Locascio, L. E. Anal. Chem. 2000, 72, 4899.

13. Barker, S. L. R.; Ross, D.; Tarlov, M. J.; Gaitan, M.; Locascio, L. E. Anal. Chem. 2000, 72, 5925.

14. Liu, Y.; Fanguy, J. C.; Bledsoe, J. M.; Henry, C. S. Anal. Chem. 2000, 72, 5939.

15. Lin, Y.-W.; Chang, H.-T. J. Chromatogr. A 2005, 1073, 191.

16. Morris, T.; Kloepper, K.; Wilson, S.; Szulczewski, G. J. Colloid Interf. Sci. 2002, 254, 49.

17. Nath, N.; Chilkoti, A. Anal. Chem. 2004, 76, 5370.

18. Grabar, K. C.; Smith, P. C.; Musick, M. D.; Davis, J. A.; Walter, D. G.; Jackson, M. A.; Guthrie, A. P.; Natan, M. J. J. Am. Chem. Soc. 1996, 118, 1148.

19. Karadas, F.; Ertas, G.; Ozkaraoglu, E.; Suzer, S. Langmuir $\mathbf{2 0 0 5}, 21,437$.

20. Cant, N. E.; Zhang, H.-L.; Critchley, K.; Mykhalyk, T. A.; Davies, G. R.; Evans, S. D. J. Phys. Chem. B. 2003, 107, 13557.

21. Santhanam, V.; Andres, R. P. Nano Lett. 2004, 4, 41.

22. Tanaka, H.; Mitsuishi, M.; Miyashita, T. Langmuir 2003, 19, 3103.

23. Krasteva, N.; Besnard, I.; Guse, B.; Bauer, R. E.; Mullen, K.; Yasuda, A.; Vossmeyer, T. Nano Lett. 2002, 2, 551.

24. Jiang, C.; Markutsya, S.; Tsukruk, V. V. Langmuir 2004, 20 , 882.

25. (a) Sönnichsen, C.; Reinhard, B. M.; Liphardt, J.; Alivisatos, A. P. Nat. Biotechnol. 2005, 23, 741. (b) Lin, F. Y. H.; Sabri, M.; Alirezaie, J.; Li, D.; Sherman, P. M. Clin. Diagn. Lab Immunol. 2005, 12, 418. (c) El-Sayed, I. H.; Huang, X.; El-Sayed, M. A. Nano Lett. 2005, 5, 829. (d) Lu, Y.; Liu, G. L.; Kim, J.; Mejia, Y. X.; Lee, L. P. Nano Lett. 2005, 5, 119.

26. Liu, Y.; Ganser, D.; Schneider, A.; Liu, R.; Grodzinski, P.; Kroutchinina, N. Anal. Chem. 2001, 73, 4196.

27. Hosokawa, K.; Fujii, T.; Endo, I. Anal. Chem. 1999, 71, 4781.

28. Mock, J. J.; Oldenburg, S. J.; Smith, D. R.; Schultz, D. A.; Schultz, S. Nano Lett. 2002, 2, 465.

29. Tang, Z.; Wang, Y.; Kotov, N. A. Langmuir 2002, 18, 7035.

30. Schaaf, P.; Voegel, J.-C.; Senger, B. J. Phys. Chem. 2004, 104, 2204.

31. Minko, S.; Kiriy, A.; Gorodyska, G.; Stamm, M. J. Am. Chem. Soc. 2002, 124, 3218.

32. Park, S.-H.; Im, J.-H.; Im, J.-W.; Chun, B.-H.; Kim, J.-H. Microchem. J. 1999, 63, 71.

33. Zhao, N.; Shi, F.; Wang, Z.; Zhang, X. Langmuir 2005, 21, 4713.

34. Hua, F.; Cui, T.; Lvov, Y. M. Nano Lett. 2004, 5, 823.

35. Kulakovich, O.; Strekal, N.; Yaroshevich, A.; Maskevich, S.; Gaponenko, S.; Nabiev, I.; Woggon, U.; Artemyev, M. Nano Lett. 2002, 2, 1449. 
36. Olson, L. G.; Lo, Y.-S.; Beebe Jr., T. P.; Harris, J. M. Anal. Chem. 2001, 73, 4268.

37. Dragnea, B.; Chen, C.; Kwak, E.-S.; Stein, B.; Kao, C. C. J. Am. Chem. Soc. 2003, 125, 6374.

38. Chiou, S.-C.; Huang, M.-F.; Chang, H.-T. Electrophoresis
2004, 25, 2186.

39. Gunnarsson, L.; Rindzevicius, T.; Prikulis, J.; Kasemo, B.; Käll, M.; Zou, S.; Schatz, G. C. J. Phys. Chem. B 2005, 109, 1079. 